\title{
Growth Rate of Geographic Atrophy Secondary to Age-Related Macular Degeneration: A Meta-Analysis of Natural History Studies and Implications for Designing Future Trials
}

\author{
Jianyong Wang a Gui-Shuang Ying ${ }^{\mathrm{b}}$ \\ aDepartment of Ophthalmology, The First Affiliated Hospital, College of Medicine, Zhejiang University, Hangzhou, \\ PR China; ${ }^{b}$ Center for Preventive Ophthalmology and Biostatistics, Department of Ophthalmology, Perelman School \\ of Medicine, University of Pennsylvania, Philadelphia, PA, USA
}

\section{Keywords}

Geographic atrophy · Growth rate · Natural history · Sample size $\cdot$ Clinical trial

\begin{abstract}
Introduction: There is no effective treatment for geographic atrophy (GA). To help design future GA treatment trials, we conducted a meta-analysis for GA growth rate and its variability in natural history studies. Methods: Literatures were searched up to April 30, 2020. Data were extracted independently by 2 authors and analyzed using random-effects models. Results: The pooled mean GA growth rate was 1.66 $\mathrm{mm}^{2} /$ year (SD $=1.27 \mathrm{~mm}^{2} /$ year, $R^{2}=97.0 \%, p<0.001$ ) from 23 studies (3,078 patients) reported with growth rate in $\mathrm{mm}^{2} /$ year and $0.33 \mathrm{~mm} /$ year $\left(\mathrm{SD}=0.17 \mathrm{~mm} /\right.$ year, $\mathrm{I}^{2}=83.0 \%$, $p<0.001)$ from 12 studies (1,808 patients) reported with growth rate in $\mathrm{mm} /$ year. Larger mean baseline GA area in $\mathrm{mm}^{2}$ was associated with larger mean growth rate in both $\mathrm{mm}^{2} /$ year and $\mathrm{mm} /$ year $(p<0.001)$. The sample size at $85 \%$ power for detecting $15 \%$ reduction in growth rate in a 2-arm GA trial is 464 and 209 patients per arm, respectively, for using $\mathrm{mm}^{2}$ /year and $\mathrm{mm}$ /year as the primary outcome. Discussion/Conclusion: GA natural history studies had a pooled mean (SD) GA growth rate of $1.66(1.27) \mathrm{mm}^{2} /$ year or 0.33 (0.17) $\mathrm{mm} /$ year. Because GA growth rate using $\mathrm{mm} /$ year re-
\end{abstract}

quires smaller sample size than using $\mathrm{mm}^{2} /$ year, GA growth rate in $\mathrm{mm}$ /year is recommended as the primary outcome measure for future GA trials.

(c) 2020 S. Karger AG, Basel

\section{Introduction}

Age-related macular degeneration (AMD) is the leading cause of blindness among the elderly in Western countries and is the third leading cause of blindness in the world affecting approximately 5 million globally $[1,2]$. Neovascular AMD and geographic atrophy (GA) are 2 forms of advanced AMD with GA accounting for approximately $20 \%$ of legal blindness in the USA [3]. While antiVEGF drugs provide effective treatment for neovascular $A M D$, there is no approved or effective treatment for GA, in spite that many GA clinical trials have been completed or are ongoing to find a viable treatment for preventing the onset of GA or for slowing down the growth of existing GA [4]. Our previous review of GA treatment trials registered in ClinicalTrials.Gov found that $71 \%$ of phase 3 GA trials used GA growth rate as the primary outcome measure [4]. Well-designed GA trials require sufficient sample size to provide good power for detecting the treatment effect by comparing the GA growth rate between karger@karger.com

www.karger.com/ore

Karger $\stackrel{2}{=}$ (c) 2020 S. Karger AG, Base

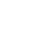

\footnotetext{
Gui-Shuang Ying

Department of Ophthalmology

Center for Preventative Ophthalmology and Biostatistics

University of Pennsylvania, Philadelphia, PA 19104 (USA)

gsying@ pennmedicine.upenn.edu
} 
the treated arm and the control (placebo or sham) arm. The GA growth rate and its variation from the observational studies or from the control arm of previous GA treatment trials provide important information on the natural GA growth rate and its variation (e.g., standard deviation, $\mathrm{SD}$ ), which are needed for designing the future GA treatment trials. Thus, we performed a meta-analysis for the GA growth rate and its variation using data from natural history studies (i.e., observational GA growth studies and control arm of GA clinical trials for GA).

\section{Methods}

This meta-analysis was conducted following the Meta-analysis of Observational Studies in Epidemiology (MOOSE) statement [5].

\section{Data Sources and Searches}

The PubMed, EMBASE, Web of Science, and Cochrane Library databases were searched up to April 30, 2020, using combinations of the following search terms: "geographic atrophy," "macular atrophy," "atrophy," "macular degeneration," "progression," "growth," and "enlargement." No language restrictions were imposed.

The titles and abstracts of the retrieved articles were reviewed to exclude any clearly irrelevant studies. The full texts of the remaining articles were reviewed to determine whether they contained any information on the growth rate of GA secondary to AMD. To find all relevant studies, the reference lists of systematic reviews on GA $[6,7]$, as well as the reference lists of each included study, were also comprehensively checked.

\section{Study Selection and Data Extraction}

The inclusion criteria for this meta-analysis were as follows: (1) the study patients had GA secondary to AMD, either already present at baseline (prevalent cases) or newly developed during followup (incident cases); (2) patients were not treated for GA, which included patients in the observational studies of GA growth or patients in the control arm of GA treatment trials who were treated only with placebo or sham; (3) the GA lesion size was measured at least in 2 time points for determining the GA growth rate using image modalities including color fundus photography (CFP), fundus autofluorescence (FAF), fluorescein angiography, or spectral domain optical coherence tomography (SD-OCT); and (4) the GA growth rate (either in $\mathrm{mm}^{2}$ /year or $\mathrm{mm}$ /year) and its variation (either SD or standard error) were reported. We excluded studies of GA in the patients with exudative AMD who were treated with anti-VEGF. We (J.Y.W. and G.S.Y.) independently assessed the eligibility of studies and extracted data from each eligible study, and discrepancies were discussed to reach an agreement.

The study characteristics and results from eligible studies were extracted, including the name of the first author, the name of the study, the year of publication, the sample size (number of eyes and number of patients), the mean baseline GA area, the length of follow-up (in years), the imaging modalities used for measuring GA size, the mean GA growth rate (either in $\mathrm{mm}^{2}$ /year or square root transformed in $\mathrm{mm} /$ year) and SD, and the nature of the GA study (observational study or the control arm of the GA treatment trial).

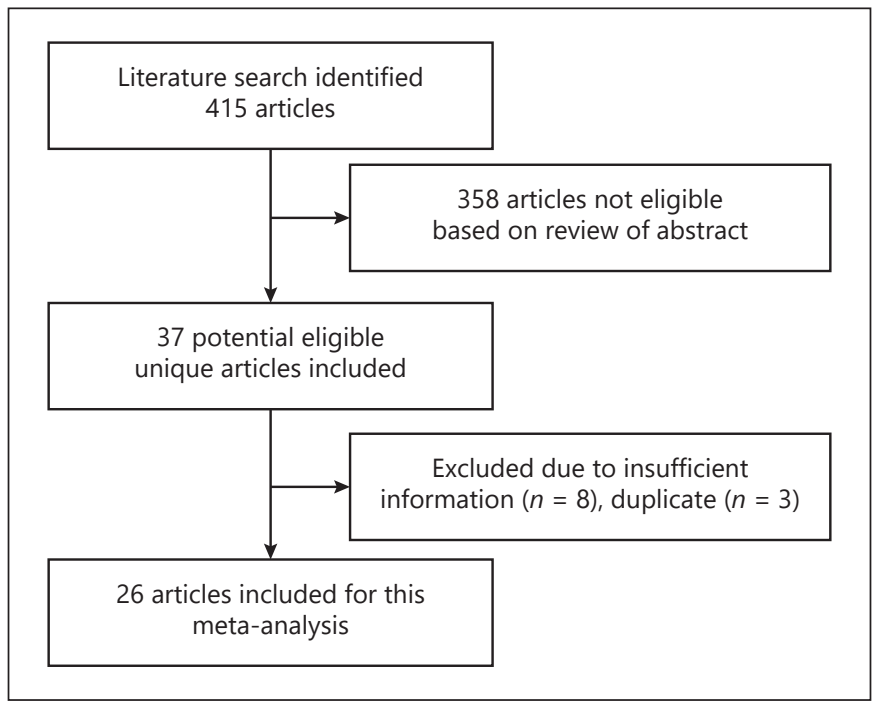

Fig. 1. The flowchart for the selection of 26 GA natural history studies for the meta-analysis of GA growth rate from 3,666 eyes of 3,222 subjects. GA, geographic atrophy.

When a study published multiple papers on the GA growth rate during various lengths of follow-up, the results from the most recent paper with longest follow-up were used. For the GA treatment trials, only the data from the patients in the control group with placebo treatment or sham treatment were extracted. For studies that only reported the median (interquartiles) of GA size, we calculated mean (SD) using a calculator at the link: http://www.comp. hkbu.edu.hk/ xwan/median2mean.html [8]. The extracted data used for this meta-analysis are available from the corresponding author upon request. Ethical approval was not required because this is the meta-analysis of the published data.

\section{Statistical Analysis}

Open Meta-Analyst software [9] (version for Windows 8, downloaded from http://www.cebm.brown.edu/open_meta/ download.html) was used for the statistical analysis. Random-effects models were used to estimate the pooled GA growth rate and its $95 \%$ confidence intervals ( $95 \% \mathrm{CI}$ ). Since some studies reported GA growth in $\mathrm{mm}^{2} /$ year and other studies reported growth rate in $\mathrm{mm}$ /year from square root transformation of GA area in $\mathrm{mm}^{2}$ / year, we performed 2 separate meta-analysis for GA growth rate in $\mathrm{mm}^{2} /$ year and in $\mathrm{mm}$ /year. We performed the meta-regression analysis to evaluate whether the mean baseline GA lesion size in $\mathrm{mm}^{2}$ was associated with the mean GA growth rate calculated as $\mathrm{mm}^{2} /$ year and $\mathrm{mm} /$ year. The percentage of total variation in the estimate of GA growth rate across included studies due to heterogeneity was assessed using the $I^{2}$ statistic [10]. $I^{2}$ ranges from 0 to $100 \%$ ( $0 \%$ represents no heterogeneity) with higher value representing larger heterogeneity. A sensitivity analysis, removing 1 study one at a time, was performed to assess the robustness of pooled mean GA growth rate. For studies that reported GA growth rates from both FAF and CFP, we used the GA growth rate from FAF for the overall meta-analysis of GA growth rate (as their GA growth rate was very similar). 


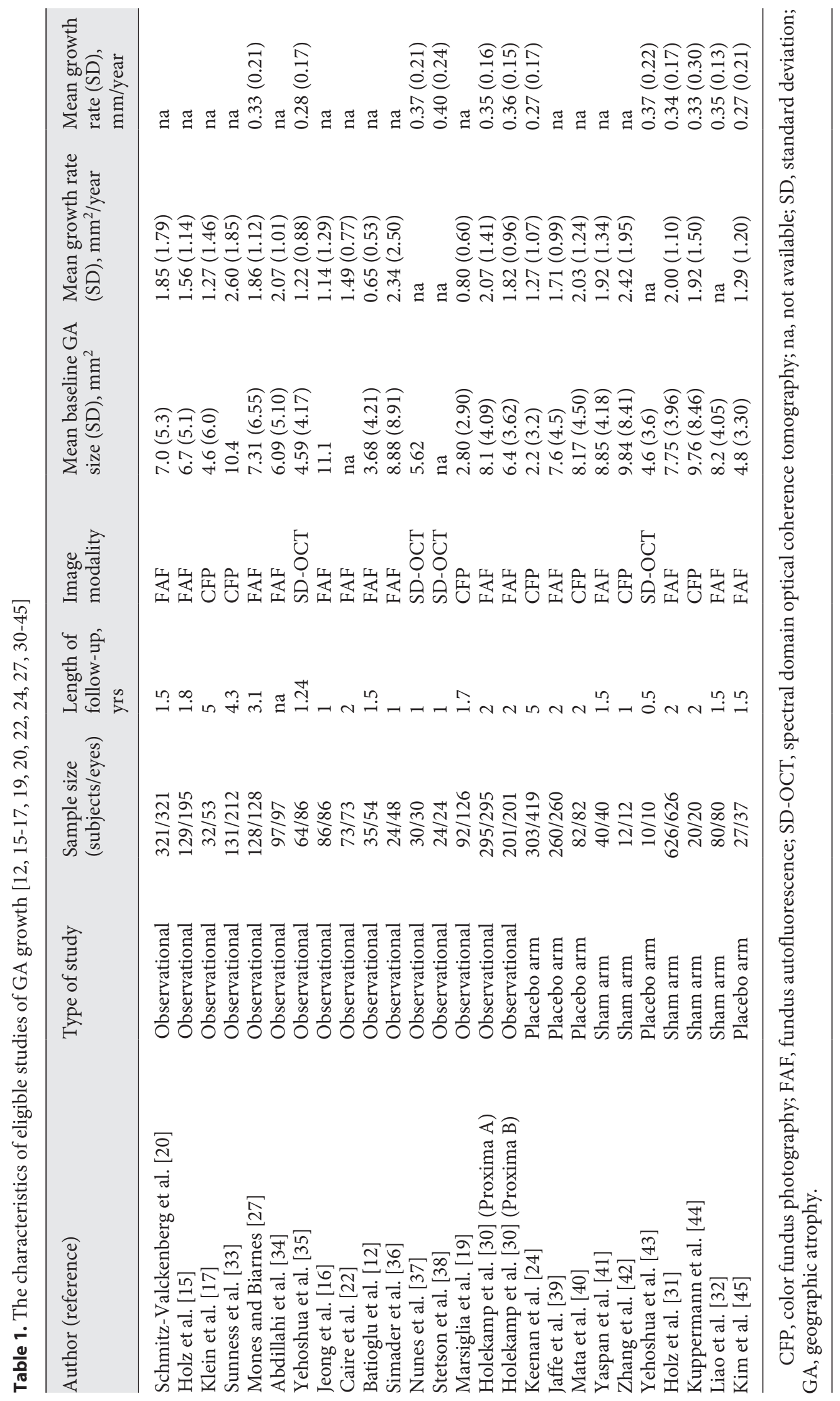


Studies

Abdillahi 2014 [34]

Klein 2008 [17]

Batioglu 2014 [12]

Zhang 2011 [42]

Caire 2014 [22]

Holz 2018 [31]

Holz 2007 [15]

Mata 2013 [40]

Mones 2018 [27]

Schmitz-Valckenberg 2016 [20]

Jaffe 2015 [39]

Jeong 2014 [16]

Yaspan 2017 [41]

Marsiglia 2013 [19]

Simader 2014 [36]

Sunness 2007 [33]

Yehoshua 2011 [35]

Kuppermann 2020 [44]

Kim 2020 [45]

Keenan 2018 [24]

Holekamp 2019a [24]

Holekamp 2019b [24]

Overall $\left(R^{2}=96.98 \%, p<0.001\right)$
Estimate (95\% C.I.)

$2.070(1.869,2.271)$

$1.270(0.877,1.663)$

$0.650(0.509,0.791)$

$2.420(1.317,3.523)$

$1.490(1.313,1.667)$

$1.998(1.910,2.086)$

$1.560(1.400,1.720)$

$2.030(1.762,2.298)$

$1.860(1.666,2.054)$

$1.850(1.654,2.046)$

$1.707(1.587,1.827)$

$1.140(0.867,1.413)$

$1.915(1.500,2.330)$

$0.800(0.695,0.905)$

$2.340(1.633,3.047)$

$2.600(2.351,2.849)$

$1.220(1.034,1.406)$

$1.920(1.263,2.577)$

$1.290(0.837,1.743)$

$1.270(1.150,1.390)$

$2.070(1.909,2.231)$

$1.820(1.687,1.953)$

$1.664(1.441,1.888)$

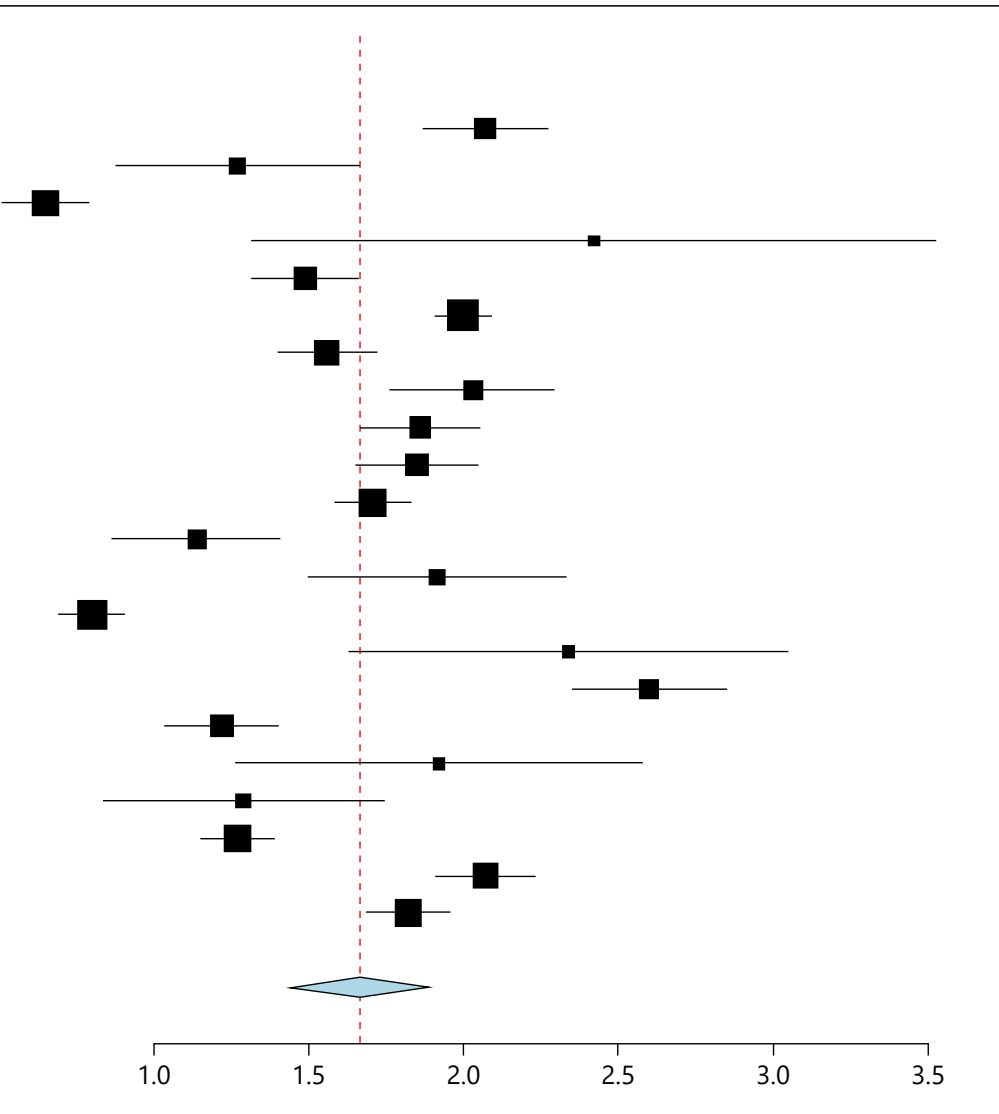

Fig. 2. Forest-tree plot for the GA growth rate in $\mathrm{mm}^{2} /$ year that included 23 studies of 3,471 eyes from 3,078 patients. GA, geographic atrophy.

Because the sample size calculation for the future GA treatment trial requires the information on the SD of GA growth rate, we calculated the pooled SD of GA growth rate in both $\mathrm{mm}^{2} /$ year and $\mathrm{mm}$ /year from all eligible GA studies using the following formula:

$$
\mathrm{SD}_{\text {pooled }}=\sqrt{\frac{\left(n_{1}-1\right) s_{1}^{2}+\left(n_{2}-1\right) s_{2}^{2}+\left(n_{3}-1\right) s_{3}^{2}+\mathrm{L}+\left(n_{k}-1\right) s_{k}^{2}}{\left(n_{1}+n_{2}+n_{3}+\mathrm{L}+n_{k}-k\right)}}
$$

where $n_{1}, n_{2}, \ldots n_{k}$ are the number of subjects from each of $k$ studies and $s_{1}, s_{2}, \ldots s_{k}$ is the SD of GA growth rate from $k$ studies.

Based on the estimated SD for the GA growth rate in both $\mathrm{mm}^{2}$ / year and $\mathrm{mm} /$ year, we calculated the sample size for 2-arm GA treatment trials ( 1 treatment arm and 1 control arm) using GA growth rate of either $\mathrm{mm}^{2}$ /year or $\mathrm{mm}$ /year as the primary outcome measure. The sample size calculation assumed the following: (1) 1 study eye per patient; (2) 2-sample $t$ test for comparing GA growth rate between 2 arms; (3) type I error rate of 0.05 ; and (4) $85 \%$ power for detecting various magnitude reduction in mean GA growth rate (ranging from 10 to $30 \%$ reduction of pooled mean growth rate).

\section{Results}

The literature search identified 3,222 subjects $(3,666$ eyes) from $26 \mathrm{GA}$ natural history studies that reported the mean GA growth rate (either in $\mathrm{mm}^{2} /$ year or $\mathrm{mm}$ /year or both) and provided sufficient information for meta-analysis (Fig. 1). The characteristics of these 26 studies are summarized in Table 1.

\section{GA Growth Rate in $\mathrm{mm}^{2} /$ year}

A total of 23 studies (3,471 eyes from 3,078 subjects) reported GA growth rate in $\mathrm{mm}^{2} /$ year, including 1,975 eyes from observational studies and 1,496 eyes from the control arm of GA treatment trials. A total of 7 studies used CFP, 14 studies used FAF, 1 study used both CFP and FAF, and 1 study used SD-OCT (Table 1). Across these 23 studies, the mean baseline GA area ranges from 2.2 to $11.1 \mathrm{~mm}^{2}$ and the mean GA growth rate ranges from 0.65 to $2.60 \mathrm{~mm}^{2} /$ year during the length of followup ranging from 1 to 5 years. 
Fig. 3. Scatter plot for mean GA growth rate $\left(\mathrm{mm}^{2} /\right.$ year) with mean baseline GA area (in $\mathrm{mm}^{2}$ ) with linear regression line from meta-regression. Mean GA growth rate is associated with mean baseline GA area $(p<0.001)$, with linear equation of (mean growth rate $\left[\mathrm{mm}^{2} /\right.$ year $]=0.702+$ $0.142 \times$ mean baseline GA area $\left.\left[\mathrm{mm}^{2}\right]\right)$. GA, geographic atrophy.

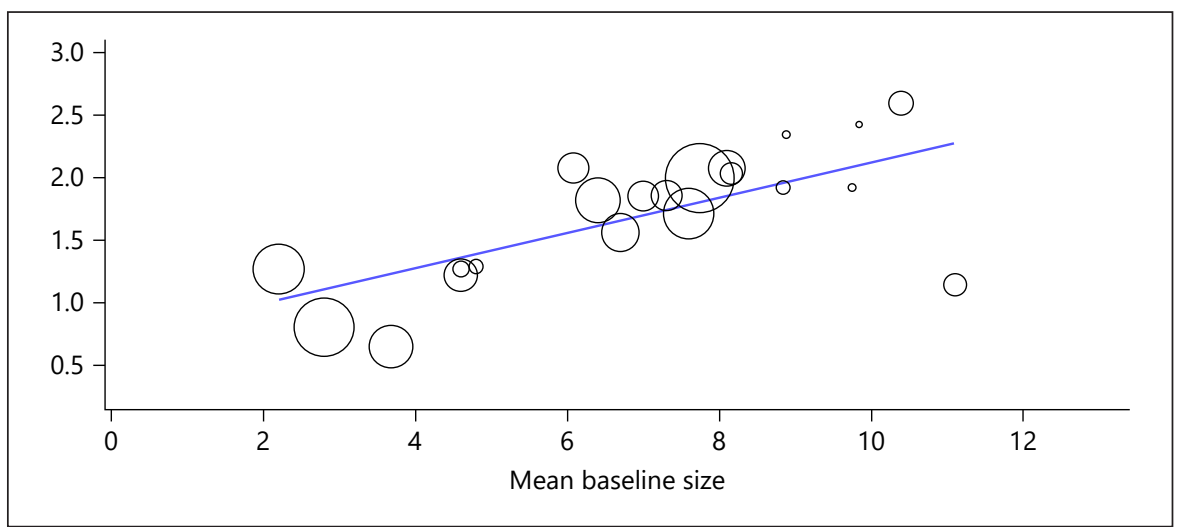

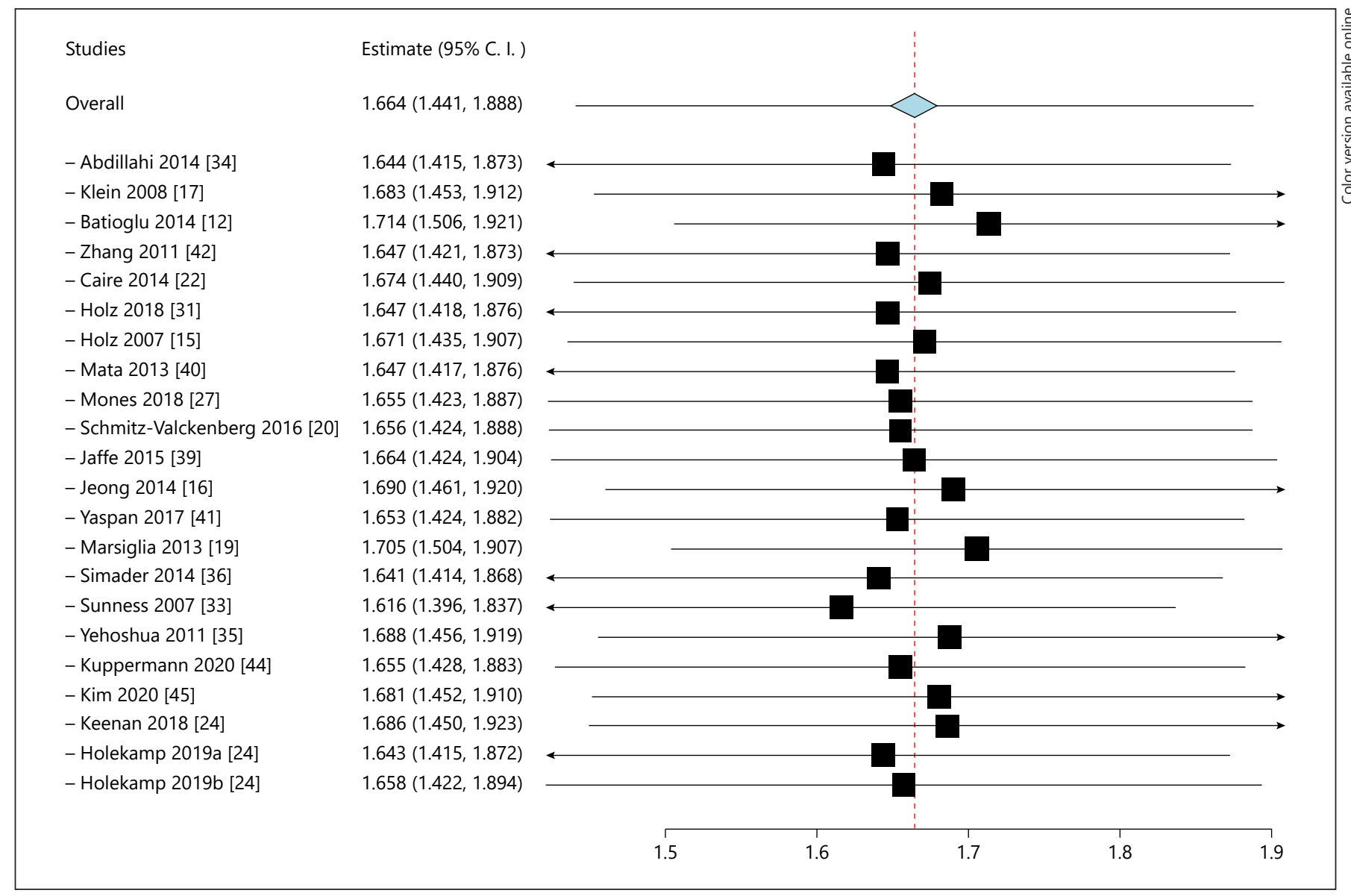

Fig. 4. Sensitivity analysis for mean GA growth rate in $\mathrm{mm}^{2} /$ year by removing 1 study at a time. It demonstrates the consistency of the pooled estimate of mean GA growth rate. GA, geographic atrophy.

The pooled overall mean GA growth rate is $1.66 \mathrm{~mm}^{2} /$ year (pooled SD $=1.27 \mathrm{~mm}^{2} /$ year, 95\% CI: $1.44-1.89$ $\mathrm{mm}^{2}$ /year, Fig. 2). There was substantial heterogeneity of GA growth rate across studies $\left(I^{2}=97.0 \%, p<0.001\right)$. In meta-regression analysis, larger baseline GA area (in $\mathrm{mm}^{2}$ ) was significantly associated with larger mean GA growth rate (slope $=0.142 \mathrm{~mm}^{2} /$ year, $p<0.001$ ) (Fig. 3). For every $\mathrm{mm}^{2}$ increase in mean baseline GA area, the mean GA growth rate increased by $0.14 \mathrm{~mm}^{2} /$ year $(95 \%$ CI: $0.08-0.21 \mathrm{~mm}^{2} /$ year). 


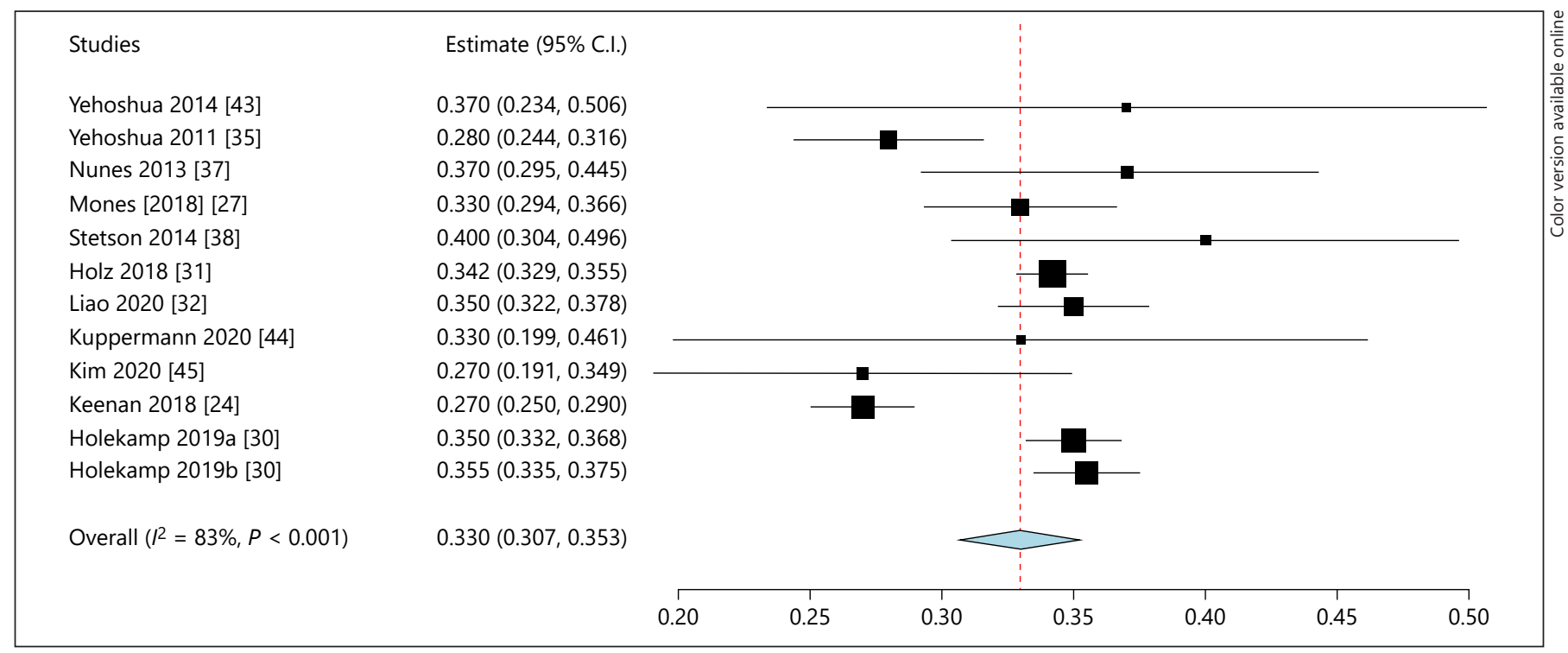

Fig. 5. Forest-tree plot for the mean GA growth rate in $\mathrm{mm} /$ year that included 12 studies of 1,956 eyes from 1,808 subjects. GA, geographic atrophy.

Fig. 6. Scatter plot for mean GA growth rate $(\mathrm{mm} /$ year) with mean baseline GA area $\left(\mathrm{mm}^{2}\right)$ with linear regression line from meta-regression. Mean GA growth rate $(\mathrm{mm} /$ year) is associated with mean baseline GA area $(p<0.0001)$, with linear equation of (mean growth rate $[\mathrm{mm} /$ year $]=$ $0.247+0.013 \times$ mean baseline GA area $\left.\left[\mathrm{mm}^{2}\right]\right)$. GA, geographic atrophy.

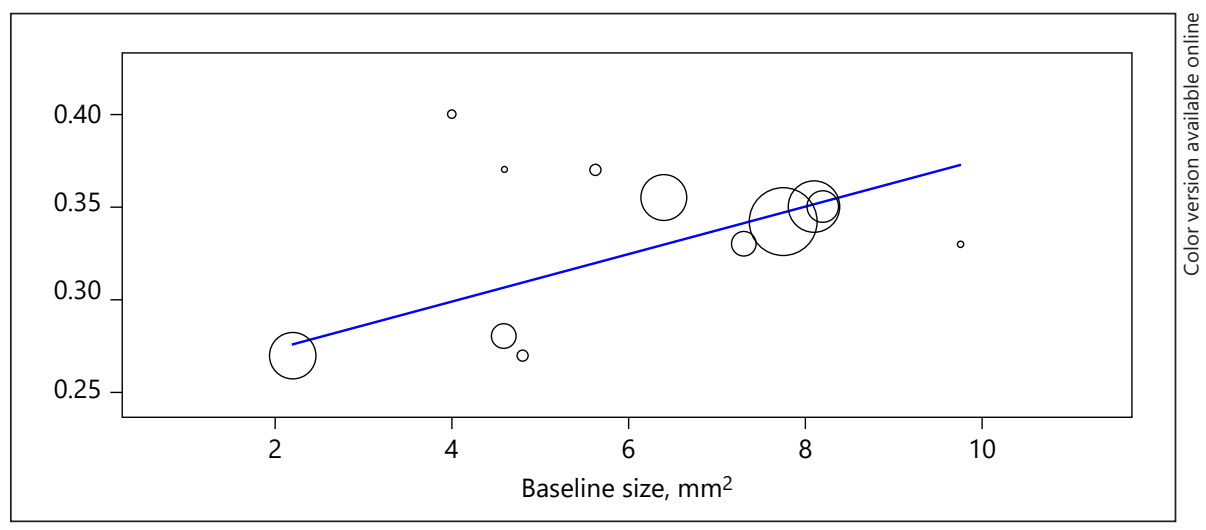

To evaluate the robustness of our pooled estimate of a mean GA growth rate of $1.66 \mathrm{~mm}^{2} /$ year, we performed a sensitivity analysis by removing 1 study at a time and recalculating the GA growth rate. In this sensitivity analyses, the pooled mean growth rate ranged from 1.62 to 1.71 $\mathrm{mm}^{2}$ /year (Fig. 4), indicating the robustness of our estimate of the mean GA growth rate.

\section{Estimate of GA Growth Rate in $\mathrm{mm} /$ year}

A total of 12 studies (1,956 eyes, 1,808 subjects) reported GA growth rate in $\mathrm{mm} /$ year, including 904 eyes from observational studies and 1,052 eyes from the control arm of GA treatment trials. A total of 2 studies used CFP, 6 studies used FAF, and 4 studies used SD-OCT (Table 1). Across these 12 eligible studies, the mean baseline
GA area ranged from 2.2 to $9.8 \mathrm{~mm}^{2}$, the mean GA growth rate ranged from 0.27 to $0.40 \mathrm{~mm} /$ year, and the mean follow-up length ranged from 0.5 to 5 years.

The pooled mean GA growth rate was $0.33 \mathrm{~mm} /$ year (pooled SD $=0.17 \mathrm{~mm} /$ year, 95\% CI: 0.31-0.35 mm/year) with substantial heterogeneity across studies $\left(I^{2}=83.0 \%\right.$, $p<0.001$ ) (Fig. 5). The mean baseline GA area in $\mathrm{mm}^{2}$ was significantly associated with GA growth rate in $\mathrm{mm} /$ year ( slope $=0.013 \mathrm{~mm} /$ year, $p<0.001$ ) (Fig. 6). For every $\mathrm{mm}^{2}$ increase in mean baseline GA area, the mean GA growth rate increased by $0.013 \mathrm{~mm} /$ year (95\% CI: $0.008-$ $0.017 \mathrm{~mm}^{2} /$ year). In the sensitivity analysis, the pooled mean GA growth rate ranged from 0.326 to $0.338 \mathrm{~mm} /$ year (Fig. 7), indicating the very robustness of estimate of the GA growth rate in $\mathrm{mm} /$ year. 


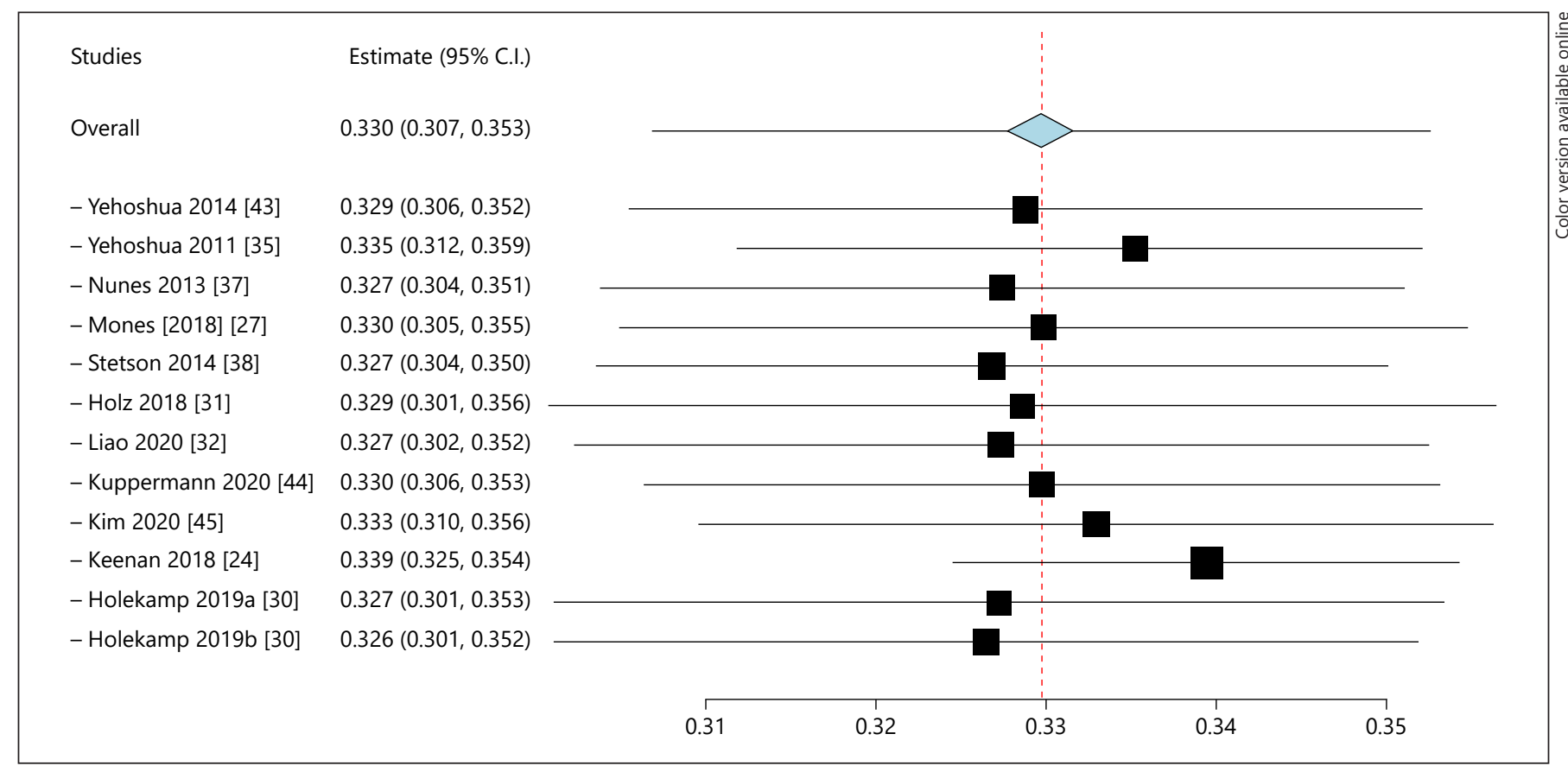

Fig. 7. Sensitivity analysis for GA growth rate in $\mathrm{mm} /$ year by removing 1 study at a time. It demonstrates the consistency of the pooled estimate of mean GA growth rate. GA, geographic atrophy.

Table 2. Sample size required for the GA treatment trial based on pooled SD of GA growth rate (in $\mathrm{mm}^{2} /$ year or $\mathrm{mm} / \mathrm{year}$ ) under various assumption reduction in GA growth rate*

\begin{tabular}{|c|c|c|c|c|c|}
\hline \multicolumn{3}{|c|}{ GA growth rate, $\mathrm{mm}^{2} /$ year } & \multicolumn{3}{|c|}{ GA growth rate, $\mathrm{mm} /$ year } \\
\hline 0.17 & 10 & 1,003 & 0.033 & 10 & 478 \\
\hline 0.25 & 15 & 464 & 0.050 & 15 & 209 \\
\hline 0.50 & 30 & 117 & 0.099 & 30 & 54 \\
\hline
\end{tabular}

$\mathrm{SD}$, standard deviation; GA, geographic atrophy. * Assuming type 1 error rate of 5\%, statistical power of $85 \%, \mathrm{SD}$ of $1.27 \mathrm{~mm}{ }^{2} /$ year and $0.17 \mathrm{~mm} /$ year for GA growth rate, and 2-sample $t$ test for comparing GA growth rate between the treated arm and control arm, with 1 eye per patient included in the GA treatment trial.

\section{Sample Size for Future GA Trial Based on Pooled SD}

of GA Growth Rate

Based on the pooled mean and SD of GA growth rate (1.66 [1.27] $\mathrm{mm}^{2} /$ year or 0.33 [0.17] $\mathrm{mm} /$ year), we calculated the sample size ( 1 study eye per patient) for future 2 -arm GA treatment trials ( 1 treatment arm and 1 control arm) using GA growth rate of either $\mathrm{mm} 2 /$ year or $\mathrm{mm}$ /year as the primary outcome measure. The sample size provided in Table 2 assumed 85\% power for detecting various magnitude reduction in mean GA growth rate (ranging from 10 to $30 \%$ reduction of pooled mean growth rate) in the GA treatment arm compared to the control arm. With the same $\%$ reduction in growth rate, the required sample size using GA growth rate in $\mathrm{mm} /$ year as the primary outcome measure was much smaller than that of using GA growth rate in $\mathrm{mm}^{2} /$ year as the primary outcome measure. For exam- 
ple, the required sample size for detecting $15 \%$ reduction in growth rate was 464 patients per group for using GA growth in $\mathrm{mm}^{2}$ /year and only 209 patients per group for using GA growth in $\mathrm{mm} /$ year (Table 2).

\section{Discussion}

This study performed comprehensive meta-analysis for the GA growth rate and its variation from natural history studies of GA growth. Our meta-analysis found that the pooled mean GA growth rate (SD) was 1.66 (1.27) $\mathrm{mm}^{2} /$ year or $0.33(0.17) \mathrm{mm} /$ year. We also found that mean GA growth rate calculated in either $\mathrm{mm}^{2}$ /year or $\mathrm{mm}$ /year was significantly associated with mean baseline GA area in $\mathrm{mm}^{2}$, with smaller baseline GA area having lower GA growth rate. This meta-analysis provides key information on the natural GA growth rate and its variation that are needed for designing the future GA treatment trials.

The change of total GA area over time is the most frequently used and accepted endpoint for assessing the efficacy of therapeutic intervention in GA clinical trials [4, 11]. Our previous systematic review of registered GA treatment trials in ClinicalTrials.Gov found that GA growth rate was the most common outcome measure, used as a primary outcome in $71 \%$ of phase 3 trials and as a secondary outcome in $31 \%$ of phase 2 trials. In designing GA treatment trials, the natural GA growth rate and its variation from eyes without any intervention are needed for sample size determination. Our comprehensive meta-analysis provides this needed information for future GA treatment trials that use GA growth rate in either $\mathrm{mm}^{2}$ /year or $\mathrm{mm} /$ year as the primary outcome measure.

Previous studies consistently showed that eyes with larger baseline GA lesion size had faster GA growth [12-21]. Consistent with these studies, this meta-analysis also found that studies with larger mean baseline GA area reported higher mean GA growth rate. For every $\mathrm{mm}^{2}$ increase in the mean baseline GA area, the mean GA growth rate increased by $0.142 \mathrm{~mm}^{2} /$ year or $0.013 \mathrm{~mm} /$ year. Thus, the baseline GA area should be considered in designing the GA treatment trials. Besides baseline GA size, previous studies also found that several other clinical and genetic factors were associated with faster GA growth, including the noncentrality, multifocality, bilateral GA, current smoking, ARMS2 risk genotype, $\mathrm{C} 3$ nonrisk genotype, and APOE nonrisk genotypes $[15,17,22-26]$. These risk factors for faster
GA growth should be considered in the design and analysis for GA treatment trials.

Besides the meta-analysis for the mean GA growth rate, we also calculated the pooled SD for GA growth rate in both $\mathrm{mm}^{2}$ /year and $\mathrm{mm}$ /year to help design the future GA treatment trials because SD is a key parameter needed for sample size determination. Using the pooled SD and the natural mean GA growth rate, we calculated the sample size for detecting various treatment effect (10-30\% reduction of the mean GA growth rate in either $\mathrm{mm}^{2} /$ year or $\mathrm{mm} /$ year compared to the control arm). Interestingly, for detecting the same \% of reduction in GA growth rate, we found that sample size using GA growth rate in $\mathrm{mm} /$ year was much smaller than using growth rate in $\mathrm{mm}^{2}$ / year. For example, the required sample size for detecting $15 \%$ reduction in mean GA growth rate is 464 patients per group for using $\mathrm{mm}^{2} /$ year as the primary outcome and is only 209 patients per group for using $\mathrm{mm}$ /year. This finding suggests that future GA treatment trials may consider using GA growth rate in $\mathrm{mm}$ /year rather than $\mathrm{mm}^{2} /$ year as the primary outcome measure.

Besides the advantage of reduced sample size, using GA growth rate in $\mathrm{mm}$ /year as the primary outcome may minimize the impact of baseline GA size on the GA growth rate because previous studies found that square root transformation decreased test-retest variability and the dependence of GA growth rate on baseline lesion size [12-21] although a recent study suggested that square root transformation did not completely eliminate the dependence of GA growth rate on the baseline size [27]. Use of the square root transformation assumed that the leading edge of a single GA lesion expands at a relatively constant rate; that is, its radius increases over time in a relatively linear fashion. Because of the relationship between radius and area $\left(\pi r^{2}\right)$, the GA area in $\mathrm{mm}^{2}$ would be associated with an exponential increase over time. Hence, comparison using change in area over time would artefactually suggest that larger GA lesions grow much faster than smaller lesions. However, this artifact can be minimized (may not be completely eliminated) by using change over time in the square root of area, so that GA growth rate can be considered at the level of increase in radius rather than area. In this way, fair comparison might be made between treatment groups for the growth rate of various baseline GA size. However, using the GA growth rate in $\mathrm{mm}$ /year as the primary outcome measure has limitation in that the interpretation of GA growth rate in $\mathrm{mm}$ /year is less straightforward than in $\mathrm{mm}^{2}$ /year because the GA size was measured in $\mathrm{mm}^{2}$, and the square root transformation assumes the GA lesion is circular and unifocal, which may not be the case for most 
GA lesions Thus, the dependence of GA growth rate on baseline GA size may still be existent even after square root transformation as shown in our meta-analysis.

If validated in future studies, our finding of the dependence of GA growth rate (in $\mathrm{mm}^{2} /$ year or $\mathrm{mm}$ /year) on the baseline GA size (in $\mathrm{mm}^{2}$ ) has several important implications on the design and analysis of the future GA treatment trials. First, the trial enrollment criterion should consider baseline GA size. Because larger baseline GA size is associated with larger GA growth rate, enrolling eyes with larger GA size may increase the opportunity of observing treatment effect over a shorter followup time period. Second, baseline GA size should be made comparable between treatment groups, such as through stratified randomization by baseline GA size. Third, the statistical modeling of GA growth needs to incorporate the baseline GA size. For the GA treatment trials with long-term follow-up (e.g., >2 years of follow-up), the GA size increases substantially over years which implies the GA growth rate also increases over time. Thus, the assumption of constant GA growth rate may not be held. The nonlinear GA growth model may be needed to allow for the increasing GA growth rate over time.

Different from the previous systematic review and meta-analysis of GA growth [7, 28, 29], this study is unique in that our meta-analysis is restricted to natural history eyes (from observational studies or control arm of GA trials) and is the most comprehensive meta-analysis to date that evaluated the overall GA growth rate and its variation calculated in both $\mathrm{mm}^{2} /$ year and $\mathrm{mm}$ /year. Our metaanalysis included several recently published large GA studies including the Proxima natural history study of 496 eyes [30], 2 phase 3 trials (Chroma and Spectri) involving a total of 626 eyes in the control arm [31], the AREDS2 study involving 419 eyes in the placebo group [24], and the APL-2 trial with 80 eyes in the control arm [32]. Our comprehensive meta-analysis was based on 26 eligible studies (involving 3,666 eyes of 3,222 patients) with the mean baseline GA area ranging from 2.2 to 11.1 $\mathrm{mm}^{2}$, representing wide range of eyes with GA. Thus, our study provides the most robust estimate of GA growth rate and its variation, which will be useful for designing the future GA treatment trials.

In conclusion, our comprehensive meta-analysis provided a pooled mean (SD) GA growth rate of 1.66 (1.27) $\mathrm{mm}^{2} /$ year and $0.33(0.17) \mathrm{mm} /$ year. The mean growth rate calculated in either $\mathrm{mm}^{2}$ /year or $\mathrm{mm}$ /year was dependent on their mean baseline GA area. Using GA growth rate in $\mathrm{mm}$ /year may have the advantage of smaller sample size than using growth rate in $\mathrm{mm}^{2}$ /year. Our meta-analysis provides key information on the natural growth of GA for designing the future GA treatment trials.

\section{Statement of Ethics}

This research complies with the guidelines for human studies in accordance with the World Medical Association Declaration of Helsinki. Ethical approval was not required because this is the meta-analysis of the published data.

\section{Conflict of Interest Statement}

None of the authors has any financial or nonfinancial interest.

\section{Funding Sources}

The authors did not receive any funding.

\section{Author Contributions}

Dr. Jianyong Wang wrote the main manuscript text and Dr. Gui-shuang Ying performed the statistical analysis, prepared all the tables and figures for the paper, and reviewed and approved the manuscript.

\section{References}

1 Resnikoff S, Pascolini D, Etya'ale D, Kocur I, Pararajasegaram R, Pokharel GP, et al. Global data on visual impairment in the year 2002. Bull World Health Organ. 2004;82(11):844-51.

2 Wong WL, Su X, Li X, Cheung CM, Klein R, Cheng CY, et al. Global prevalence of age-related macular degeneration and disease burden projection for 2020 and 2040: a systematic review and meta-analysis. Lancet Glob Health. 2014;2(2):e106-16.

Meta-Analysis for Geographic Atrophy Growth Rate
3 Holz FG, Strauss EC, Schmitz-Valckenberg S, van Lookeren Campagne M. Geographic atrophy: clinical features and potential therapeutic approaches. Ophthalmology. 2014; 121(5):1079-91.

4 Cheng QE, Gao J, Kim BJ, Ying GS. Design characteristics of geographic atrophy treatment trials: systematic review of registered trials in ClinicalTrials.gov. Ophthalmol Retina. 2018;2(6):518-25.
5 Stroup DF, Berlin JA, Morton SC, Olkin I, Williamson GD, Rennie D, et al. Meta-analysis of observational studies in epidemiology: a proposal for reporting. Meta-analysis Of Observational Studies in Epidemiology (MOOSE) group. JAMA. 2000;283(15):200812. 
6 Shen L, Liu F, Grossetta Nardini H, Del Priore LV. Natural history of geographic atrophy in untreated eyes with nonexudative age-related macular degeneration: a systematic review and meta-analysis. Ophthalmol Retina. 2018;2(9):914-21.

7 Shen LL, Liu F, Grossetta Nardini HK, Del Priore LV. Fellow eye status is a biomarker for the progression rate of geographic atrophy: a systematic review and meta-analysis. Ophthalmol Retina. 2019;3(4):305-15.

8 Wan X, Wang W, Liu J, Tong T. Estimating the sample mean and standard deviation from the sample size, median, range and/or interquartile range. BMC Med Res Methodol. 2014;14:135.

9 Wallace BC, Schmid CH, Lau J, Trikalinos TA. Meta-analyst: software for meta-analysis of binary, continuous and diagnostic data. BMC Med Res Methodol. 2009;9:80.

10 Higgins JP, Thompson SG. Quantifying heterogeneity in a meta-analysis. Stat Med. 2002;21(11):1539-58.

11 Sadda SR, Chakravarthy U, Birch DG, Staurenghi G, Henry EC, Brittain C. Clinical endpoints for the study of geographic atrophy secondary to age-related macular degeneration. Retina. 2016;36(10):1806-22.

12 Batioglu F, Gedik OY, Demirel S, Ozmert E. Geographic atrophy progression in eyes with age-related macular degeneration: role of fundus autofluorescence patterns, fellow eye and baseline atrophy area. Ophthalmic Res. 2014;52(2):53-9.

13 Biarnes M, Arias L, Alonso J, Garcia M, Hijano M, Rodriguez A, et al. Increased fundus autofluorescence and progression of geographic atrophy secondary to age-related macular degeneration: the GAIN study. Am J Ophthalmol. 2015;160(2):345-53.

14 Feuer WJ, Yehoshua Z, Gregori G, Penha FM, Chew EY, Ferris FL, et al. Square root transformation of geographic atrophy area measurements to eliminate dependence of growth rates on baseline lesion measurements: a reanalysis of age-related eye disease study report no. 26. JAMA Ophthalmol. 2013;131(1):110-1.

15 Holz FG, Bindewald-Wittich A, Fleckenstein M, Dreyhaupt J, Scholl HP, SchmitzValckenberg S. Progression of geographic atrophy and impact of fundus autofluorescence patterns in age-related macular degeneration. Am J Ophthalmol. 2007;143(3): 463-72.

16 Jeong YJ, Hong IH, Chung JK, Kim KL, Kim HK, Park SP. Predictors for the progression of geographic atrophy in patients with agerelated macular degeneration: fundus autofluorescence study with modified fundus camera. Eye. 2014;28(2):209-18.

17 Klein R, Meuer SM, Knudtson MD, Klein BE. The epidemiology of progression of pure geographic atrophy: the Beaver Dam Eye Study. Am J Ophthalmol. 2008;146(5): 692-9.
18 Lindblad AS, Lloyd PC, Clemons TE, Gensler GR, Ferris FL III, Klein ML, et al. Change in area of geographic atrophy in the Age-Related Eye Disease Study: AREDS report number 26. Arch Ophthalmol. 2009; 127(9):1168-74.

19 Marsiglia M, Boddu S, Bearelly S, Xu L, Breaux BE Jr, Freund KB, et al. Association between geographic atrophy progression and reticular pseudodrusen in eyes with dry age-related macular degeneration. Invest Ophthalmol Vis Sci. 2013;54(12):7362-9.

20 Schmitz-Valckenberg S, Sadda S, Staurenghi G, Chew EY, Fleckenstein M, Holz FG. Geographic atrophy: semantic considerations and literature review. Retina. 2016;36(12): 2250-64.

21 Sunness JS, Gonzalez-Baron J, Applegate CA, Bressler NM, Tian Y, Hawkins B, et al. Enlargement of atrophy and visual acuity loss in the geographic atrophy form of agerelated macular degeneration. Ophthalmology. 1999;106(9):1768-79.

22 Caire J, Recalde S, Velazquez-Villoria A, Garcia-Garcia L, Reiter N, Anter J, et al. Growth of geographic atrophy on fundus autofluorescence and polymorphisms of $\mathrm{CFH}, \mathrm{CFB}, \mathrm{C} 3, \mathrm{FHR} 1-3$, and ARMS2 in agerelated macular degeneration. JAMA Ophthalmol. 2014;132(5):528-34.

23 Grassmann F, Fleckenstein M, Chew EY, Strunz T, Schmitz-Valckenberg S, Göbel $\mathrm{AP}$, et al. Clinical and genetic factors associated with progression of geographic atrophy lesions in age-related macular degeneration. PLoS One. 2015;10(5):e0126636.

24 Keenan TD, Agrón E, Domalpally A, Clemons TE, van Asten F, Wong WT, et al. Progression of geographic atrophy in age-related macular degeneration: AREDS2 report number 16. Ophthalmology. 2018;125(12): 1913-28.

25 Klein ML, Ferris FL III, Francis PJ, Lindblad AS, Chew EY, Hamon SC, et al. Progression of geographic atrophy and genotype in agerelated macular degeneration. Ophthalmology. 2010;117(8):1554-e1..9

26 Schmitz-Valckenberg S, Sahel JA, Danis R, Fleckenstein M, Jaffe GJ, Wolf S, et al. Natural history of geographic atrophy progression secondary to age-related macular degeneration (Geographic Atrophy Progression Study). Ophthalmology. 2016;123(2): 361-8.

27 Mones J, Biarnes M. The rate of progression of geographic atrophy decreases with increasing baseline lesion size even after the square root transformation. Transl Vis Sci Technol. 2018;7(6):40.

28 Fleckenstein M, Mitchell P, Freund KB, Sadda S, Holz FG, Brittain C, et al. The progression of geographic atrophy secondary to age-related macular degeneration. Ophthalmology. 2018;125(3):369-90.
29 Shen LL, Liu F, Nardini HG, Del Priore LV. Reclassification of fundus autofluorescence patterns surrounding geographic atrophy based on progression rate: a systematic review and meta-analysis retina; 2019.

30 Holekamp N, Wykoff CC, Schmitz-Valckenberg S, Mones J, Souied EH, Lin H, et al. Natural history of geographic atrophy secondary to age-related macular degeneration: results from the prospective proxima $\mathrm{A}$ and B clinical trials. Ophthalmology. 2020 Jun;127(6):769-83.

31 Holz FG, Sadda SR, Busbee B, Chew EY, Mitchell P, Tufail A, et al. Efficacy and safety of lampalizumab for geographic atrophy due to age-related macular degeneration: chroma and spectri phase 3 randomized clinical trials. JAMA Ophthalmol. 2018; 136(6):666-77.

32 Liao DS, Grossi FV, El Mehdi D, Gerber MR, Brown DM, Heier JS, et al. Complement C3 inhibitor pegcetacoplan for geographic atrophy secondary to age-related macular degeneration: a randomized phase 2 trial. Ophthalmology. 2020;127(2):186-95.

33 Sunness JS, Margalit E, Srikumaran D, Applegate CA, Tian Y, Perry D, et al. The longterm natural history of geographic atrophy from age-related macular degeneration: enlargement of atrophy and implications for interventional clinical trials. Ophthalmology. 2007;114(2):271-7.

34 Abdillahi H, Enzmann V, Wittwer VV, Wolf $S$, Wolf-Schnurrbusch UE. Vitreoretinal interface changes in geographic atrophy. Ophthalmology. 2014;121(9):1734-9.

35 Yehoshua Z, Rosenfeld PJ, Gregori G, Feuer WJ, Falcão M, Lujan BJ, et al. Progression of geographic atrophy in age-related macular degeneration imaged with spectral domain optical coherence tomography. Ophthalmology. 2011;118(4):679-86.

36 Simader C, Sayegh RG, Montuoro A, Azhary M, Koth AL, Baratsits M, et al. A longitudinal comparison of spectral-domain optical coherence tomography and fundus autofluorescence in geographic atrophy. Am J Ophthalmol. 2014;158(3):557-e1.

37 Nunes RP, Gregori G, Yehoshua Z, Stetson PF, Feuer W, Moshfeghi AA, et al. Predicting the progression of geographic atrophy in age-related macular degeneration with SDOCT en face imaging of the outer retina. Ophthalmic Surg Lasers Imaging Retina. 2013;44(4):344-59.

38 Stetson PF, Yehoshua Z, Garcia Filho CA, Portella Nunes R, Gregori G, Rosenfeld PJ. OCT minimum intensity as a predictor of geographic atrophy enlargement. Invest Ophthalmol Vis Sci. 2014;55(2):792-800.

39 Jaffe GJ, Schmitz-Valckenberg S, Boyer D, Heier J, Wolf-Schnurrbusch U, Staurenghi $\mathrm{G}$, et al. Randomized trial to evaluate tandospirone in geographic atrophy secondary to age-related macular degeneration: the GATE study. Am J Ophthalmol. 2015; 160(6):1226-34. 
40 Mata NL, Lichter JB, Vogel R, Han Y, Bui $\mathrm{TV}$, Singerman LJ. Investigation of oral fenretinide for treatment of geographic atrophy in age-related macular degeneration. Retina. 2013;33(3):498-507.

41 Yaspan BL, Williams DF, Holz FG, Regillo CD, Li Z, Dressen A, et al. Targeting factor $\mathrm{D}$ of the alternative complement pathway reduces geographic atrophy progression secondary to age-related macular degeneration. Sci Transl Med. 2017;9(395):eaaf1443.
42 Zhang K, Hopkins JJ, Heier JS, Birch DG, Halperin LS, Albini TA, et al. Ciliary neurotrophic factor delivered by encapsulated cell intraocular implants for treatment of geographic atrophy in age-related macular degeneration. Proc Natl Acad Sci U S A. 2011; 108(15):6241-5.

43 Yehoshua Z, de Amorim Garcia Filho CA, Nunes RP, Gregori G, Penha FM, Moshfeghi AA, et al. Systemic complement inhibition with eculizumab for geographic atrophy in age-related macular degeneration: the COMPLETE study. Ophthalmology. 2014; 121(3):693-701.
44 Kuppermann BD, Patel SS, Boyer DS, Augustin AJ, Freeman WR, Kerr KJ, et al. Phase 2 study of the safety and efficacy of brimonidine drug delivery system (brimo dds) generation 1 in patients with geographic atrophy secondary to age-related macular degeneration retina; 2020.

45 Kim BJ, Hunter A, Brucker AJ, Hahn P, Gehrs K, Patel A, et al. Orally administered alpha lipoic acid as a treatment for geographic atrophy: a randomized clinical trial. Ophthalmology Retina. 2020;4(9):889-98. 